\title{
Severe pain at the end of life: a population- level observational study
}

A. Meaghen Hagarty', Shirley H. Bush 1,2,3, Robert Talarico ${ }^{3,4}$, Julie Lapenskie ${ }^{2,3}$ and Peter Tanuseputro 1,23,4*

\begin{abstract}
Background: Pain is a prevalent symptom at the end of life and negatively impacts quality of life. Despite this, little population level data exist that describe pain frequency and associated factors at the end of life. The purpose of this study was to explore the prevalence of clinically significant pain at the end of life and identify predictors of increased pain.

Methods: Retrospective population-level cohort study of all decedents in Ontario, Canada, from April 1, 2011 to March 31, 2015 who received a home care assessment in the last 30 days of life $(n=20,349)$. Severe daily pain in the last 30 days of life using linked Ontario health administrative databases. Severe pain is defined using a validated pain scale combining pain frequency and intensity: daily pain of severe intensity.

Results: Severe daily pain was reported in $17.2 \%$ of 20,349 decedents. Increased risk of severe daily pain was observed in decedents who were female, younger and functionally impaired. Those who were cognitively impaired had a lower risk of reporting pain. Disease trajectory impacted pain; those who died of a terminal illness (i.e. cancer) were more likely to experience pain than those with frailty (odds ratio 1.66).

Conclusion: Pain is a common fear of those contemplating end of life, but severe pain is reported in less than 1 in 5 of our population in the last month of life. Certain subpopulations may be more likely to report severe pain at the end of life and may benefit from earlier palliative care referral and intervention.
\end{abstract}

Keywords: Pain, End-of-life, Palliative care, Palliative medicine, Palliative homecare

\section{Background}

Uncontrolled pain is consistently listed by patients as a primary source of fear for end-of-life care [1-3]. Palliative care aims to provide relief of pain and other physical symptoms in addition to supportive care for patients and their families at the end of life $[4,5]$. Pain is often considered one of the more treatable symptoms in palliative care [6] and a request for assistance with pain management is a common reason for referral to palliative care physician specialists and palliative care teams. Uncontrolled pain is a common reason for palliative patients to present to acute care. Nearly one in

\footnotetext{
* Correspondence: ptanuseputro@ohri.ca

${ }^{1}$ Department of Medicine, Division of Palliative Care, University of Ottawa, Ottawa, Ontario, Canada

${ }^{2}$ Bruyère Research Institute, Ottawa, Ontario, Canada

Full list of author information is available at the end of the article
}

ten emergency department visits from oncology patients in the last months of life cited pain as reason for visit [7]. Additionally, nearly $20 \%$ of patients who die in hospital experience some degree of pain [8]. Identification of those patients at risk for increased pain near the end of life is important for prompt initiation of a palliative approach and consideration of specialist palliative care referral $[6,9]$ as there is evidence that pain may be mitigated by palliative care intervention and home visits [10].

The bulk of the current data on the prevalence of pain is limited to specific populations. A systematic review examining studies between 1965 and 2006 demonstrated the pooled prevalence of pain in patients with advanced cancer was 64\% [11]. Additionally, increased pain has been reported in advanced cancer patients with mental health illnesses, including depression and anxiety [12-14]. 
Estimates of the prevalence of pain in various late stage nonmalignant populations [i.e., congestive heart failure (CHF), end-stage renal disease, chronic obstructive pulmonary disease (COPD)] range from 47 to $93 \%$ [15-17]. Studies of pain in persons with dementia have consistently demonstrated lower rates of reported pain $[18,19]$. These studies, however, do not provide a sense of the prevalence of pain across the general population at end of life nor between disease trajectories (frailty, terminal illness, organ failure, sudden death). This is important as current evidence demonstrates disparities between disease trajectory and access to palliative care services [20]. An American retrospective observational study $(N=4703)$ demonstrated clinically significant pain in $47 \%$ of the population in the last month of life (as reported using non-validated 2 question measurement: participant "often troubled by moderate to severe pain") [21]. The authors found pain was associated with proximity to death, arthritis and certain demographic factors such as sex, age, race and income. To our knowledge, no studies to date have captured in detail how pain varies across end-of-life trajectories, a wide variety of comorbid chronic diseases, home-based palliative care services, living arrangement (e.g., presence of a family caregiver) and other important patient characteristics such as impairment in function and cognition.

Our goal was to explore pain at the end of life across a wide variety of patient characteristics at a population level. To address the deficit in knowledge, we used multiple health linked databases providing access to detailed covariates in order to observe the frequency and severity of pain in the last month of life. We aimed to identify predictive or protective factors for pain at the end of life as well as potential risk factors that could be targeted for screening and prompt initiation of pain management strategies and palliative care referral.

\section{Methods}

We conducted a population-based retrospective observational study using linked health administrative databases held at ICES. Our population included all decedents in Ontario, Canada from April 1, 2011 to March 31, 2015 (most recent, complete data available at time of analysis) who received a Resident Assessment Instrument-Home Care (RAI-HC) [22] assessment in the last 30 days of life. The RAI-HC database contains RAI-HC assessments which are conducted for all Ontarians seeking to receive long-stay home care (i.e., anticipated greater than 60 days). These assessments are conducted by trained assessors with input from the clinic team, the patient's chart, the patient, and caregivers. Demographics, symptomatology, and detailed covariates were collected from each assessment. These covariates include: cognitive functioning, caregiver and living arrangements, activities of daily living (ADLs) on a 0-6 point performance scale (describing the discrete stages of loss in personal hygiene, toileting, locomotion and eating), instrumental activities of daily living (IADLs) (ordinary housework, meal preparation and phone use) [23]. Ethics approval was obtained from the Sunnybrook Health Sciences Centre Research Ethics Board in Toronto, Canada and from the Ottawa Health Science Network Research Ethics Board in Ottawa, Canada.

\section{Data sources}

Encrypted health card numbers were used as unique identifiers and linked across several administrative databases held at ICES (Additional file 1). All data were de-identified and anonymized. Deaths and demographics including age and sex were captured from the Registered Persons Database (RPDB). Postal codes of residence were used to derive neighborhood income and rurality at the time of death through the Postal Code Conversion Files which are derived from the Statistics Canada 2011 census. The presence of chronic conditions at death was captured using previously developed-and in some cases validatedchronic disease databases held at ICES [24]. A total of 17 chronic diseases were examined and the number of diseases identified was totaled for each individual [25-31]. End-of-life trajectories (i.e., frailty, terminal illness, sudden death, organ failure, other) were captured using cause of death information from the Ontario Registrar General Database (ORGD) - deaths. The International Classification of Diseases (ICD-10) codes used to group deaths into these four categories, including validation in the Canadian population, are described elsewhere [20, 32-34].

Designated palliative homecare (e.g., from nurses, nurse practitioners, and personal support workers) and physician home visits were captured between 30 days to 6 months prior to death. Palliative home care was captured when a patient was given an end-of-life designation by home care services, which allows them to access additional and often specialized palliative care services. Physician home visits were identified using physician billing claims for services delivered at home, captured in the Ontario Health Insurance Plan (OHIP) database (Additional file 2). The subset of home visits delivered by palliative care physician specialists were identified using a validated definition of greater than $10 \%$ of all billings in the previous 2 years classified as palliative care [35]. Palliative home visits and services delivered by non-physician specialties (e.g. nurse practitioners, spiritual care, personal support workers, social workers, etc.) that occurred outside of designated publicly-funded palliative home care (i.e. out-pf-pocket expenses or private insurance) is not captured in available health administrative databases and were therefore not included in our analyses.

\section{Pain at end of life}

Reported pain was captured using the RAI-HC database. Data was captured from those who received a RAI-HC 
assessment in the last month of life, the period associated with the highest pain scores [21]. A validated pain scale that combines pain intensity and frequency from the RAI-HC was applied to generate a four-point pain scale from no pain to severe pain occurring daily [36]. In this scale, severe daily pain was equivalent to an average of $5 / 10$ on a visual analog scale. As pain beyond 4/10 has been shown to be associated with decreased functional status and quality of life [37, 38], we elected to compare decedents with severe daily pain to those without severe daily pain.

\section{Analysis}

A logistic regression model was run for the primary outcome of severe daily pain in the last 30 days of life. Decedents with severe daily pain were compared to those without severe daily pain. Covariates of interest included demographics, comorbidities, functional status, and physician home visits in the 6 months to 1 month prior to death. Additionally, we examined the effect of a palliative care specialist being involved in at least one of the visits. The multivariable model examined the independent effect of potential predictors of pain that are available in health administrative databases: age, sex, neighborhood income quintile, rurality, functional status (i.e. ADLs and IADLs), Cognitive Performance Scale (CPS) [39] score, number of comorbidities, and end-of-life trajectories. All analyses were conducted using SAS 9.3 (SAS Institute Inc., Cary, NC).

\section{Results}

In Ontario, between April 1, 2011 to March 31, 2015, there were 370,524 deaths. We captured data from 20,349 decedents who received a RAI-HC assessment in the last month of life $(5.5 \%$ of total decedent population). The average age of our cohort was 81.4 years. The majority were female $(51.6 \%)$ and lived in an urban setting. $42.8 \%$ had 5 or more chronic conditions. Less than 1 in 5 people (17.2\%) reported severe daily pain using the validated pain scale (Table 1), with $30.3 \%$ of decedents reporting no pain. The majority (73.8\%) felt they had adequate pain control at baseline or with medications, however $42.4 \%$ described pain that disrupted usual activities.

\section{Factors associated with severe daily pain Demographics}

The proportion of severe daily pain was higher in those who died at a younger age (Fig. 1a).

Among female decedents, $18.4 \%$ reported severe daily pain compared to $15.9 \%$ of male decedents (Fig. 1b; Table 2). Younger decedents had a higher risk severe daily pain; $34.0 \%$ of $0-49$-year-olds compared to only
Table 1 Reported pain in decedents with a RAI-HC ${ }^{\mathrm{a}}$ assessment in the last 30 days of life

\begin{tabular}{lll}
\hline & N & COL\% \\
\hline Pain Frequency & & \\
No pain & 6181 & 30.28 \\
Less than daily & 2036 & 9.97 \\
Daily-one period & 1262 & 6.18 \\
Daily-multiple periods (e.g. morning and evening) & 10,936 & 53.57 \\
Pain Intensity & & \\
No pain & 6188 & 30.31 \\
Mild & 3211 & 15.73 \\
Moderate & 7419 & 36.34 \\
Severe or excruciating & 2776 & 13.6 \\
Times when pain is horrible & 821 & 4.02 \\
Pain disrupts usual activities & & \\
No & 11,764 & 57.62 \\
Yes & 8651 & 42.38 \\
Pain - Adequate Medication & & \\
Yes/No pain & 15,072 & 73.83 \\
Medications do not adequately control pain & 3407 & 16.69 \\
Pain present, medication not taken & 1936 & 9.48 \\
Pain Scale & & \\
No pain & 6184 & 30.29 \\
Less than daily pain & 2036 & 9.97 \\
Daily pain but not severe & 3515 & 42.52 \\
Severe daily pain & & \\
\hline & & \\
\hline
\end{tabular}

${ }^{a}$ Resident Assessment Instrument-Home Care

$13.3 \%$ of those aged $90+$. Rurality and income were not found to significantly impact risk of severe daily pain. Those with $5+$ chronic conditions reported more severe daily pain (17.8\%) than those with $0-2$ or $3-4$ (17.5 and $16.3 \%$ respectively).

Reported severe daily pain varied with living arrangements (Table 3): decedents who lived in a private community home with or without homecare reported higher severe daily pain $(17.5,18.2 \%)$ than those who lived in an assisted living or residential care facility $(15.9,14.5 \%)$. Those who lived with relatives were more likely to report severe daily pain (with spouse:18.4\%, with spouse and others:19.0\%, with child:18.7\%) compared to those who lived alone $(17.1 \%)$ or with non-relatives (15.3\%). Decedents with reported caregiver stress had increased pain compared to those with no caregiver stress (18.3\% vs. $16.4 \%)$.

\section{Functional status}

In examining ADLs (Table 3), reported severe daily pain was highest in those who were dependent (19.5\%) and 


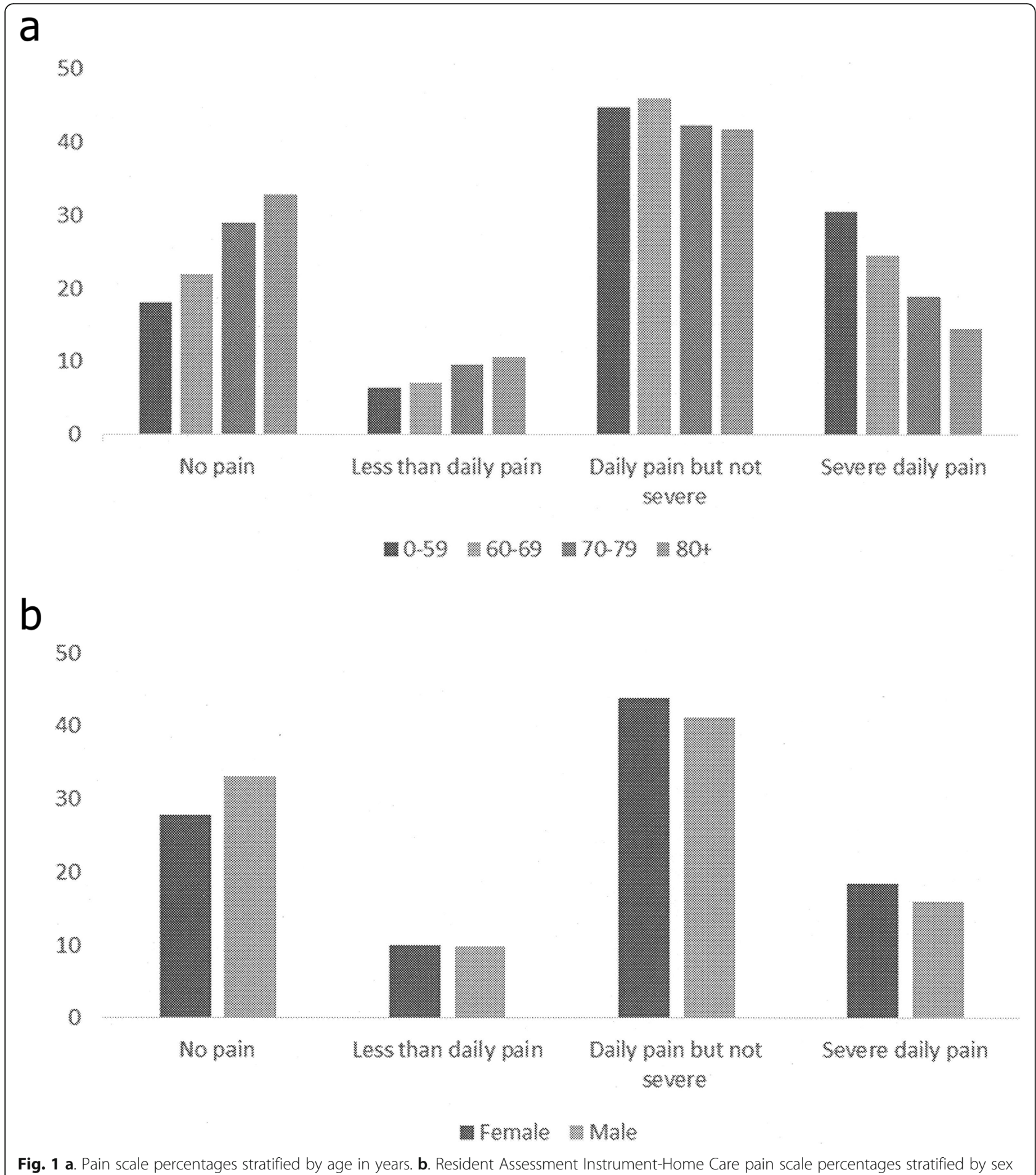

lowest in those who were totally dependent (15.8\%). Similarly, pain severity generally trended up with increasing impairment in IADLs to a maximum of great difficulty in 2 out of 3 IADLs as collected on the RAIHC (20.1\%). Those decedents with great difficulty carrying out all three IADLs reported lower than average severe daily pain $(14.7 \%)$.

\section{Clinical factors}

Reported severe daily pain decreased with worsening cognitive impairment, with $20.3 \%$ of cognitively intact persons reporting severe daily pain compared to $12.8 \%$ with very severe cognitive impairment. Pain scores varied with end-of-life trajectory. Those with frailty (e.g., dementia), organ failure (e.g., COPD or 
Table 2 Cohort characteristics by pain severity in the last 30 days of life

\begin{tabular}{|c|c|c|c|c|c|}
\hline & No severe daily pain & $(\%)$ & Severe daily pain & $(\%)$ & All \\
\hline & N & & N & & $\mathrm{N}$ \\
\hline \multicolumn{6}{|l|}{ Age } \\
\hline $0-49$ & 161 & $66.0 \%$ & 83 & $34.0 \%$ & 244 \\
\hline $50-59$ & 559 & $70.4 \%$ & 235 & $29.6 \%$ & 794 \\
\hline $60-69$ & 1452 & $75.4 \%$ & 474 & $24.6 \%$ & 1926 \\
\hline $70-79$ & 3285 & $81.0 \%$ & 773 & $19.0 \%$ & 4058 \\
\hline $80-89$ & 7181 & $84.7 \%$ & 1297 & $15.3 \%$ & 8478 \\
\hline $90+$ & 4206 & $86.7 \%$ & 643 & $13.3 \%$ & 4849 \\
\hline \multicolumn{6}{|l|}{ Sex } \\
\hline Male & 8281 & $84.1 \%$ & 1569 & $15.9 \%$ & 9850 \\
\hline Female & 8563 & $81.6 \%$ & 1936 & $18.4 \%$ & 10,499 \\
\hline \multicolumn{6}{|l|}{ Income Quintile } \\
\hline Highest & 2990 & $83.8 \%$ & 576 & $16.2 \%$ & 3566 \\
\hline High & 3141 & $82.4 \%$ & 673 & $17.6 \%$ & 3814 \\
\hline Middle & 3307 & $82.6 \%$ & 695 & $17.4 \%$ & 4002 \\
\hline Low & 3679 & $83.2 \%$ & 744 & $16.8 \%$ & 4423 \\
\hline Lowest & 3727 & $82.0 \%$ & 817 & $18.0 \%$ & 4544 \\
\hline \multicolumn{6}{|l|}{ Rurality } \\
\hline Urban & 13,807 & $82.9 \%$ & 2850 & $17.1 \%$ & 16,657 \\
\hline Rural & 3037 & $82.3 \%$ & 655 & $17.7 \%$ & 3692 \\
\hline \multicolumn{6}{|l|}{ Palliative Home Care } \\
\hline No & 13,205 & $84.1 \%$ & 2488 & $15.9 \%$ & 15,693 \\
\hline Yes & 3639 & $78.2 \%$ & 1017 & $21.8 \%$ & 4656 \\
\hline \multicolumn{6}{|l|}{ Physician Home Visit } \\
\hline No & 14,711 & $83.0 \%$ & 3008 & $17.0 \%$ & 17,719 \\
\hline Yes - Non-PC ${ }^{a}$ specialist & 1817 & $81.8 \%$ & 405 & $18.2 \%$ & 2222 \\
\hline Yes - PC specialist & 372 & $78.5 \%$ & 102 & $21.5 \%$ & 474 \\
\hline \multicolumn{6}{|c|}{ Number of Chronic Conditions } \\
\hline $0-2$ & 3744 & $82.5 \%$ & 795 & $17.5 \%$ & 4539 \\
\hline $3-4$ & 5938 & $83.7 \%$ & 1157 & $16.3 \%$ & 7095 \\
\hline $5+$ & 7162 & $82.2 \%$ & 1553 & $17.8 \%$ & 8715 \\
\hline \multicolumn{6}{|l|}{ Cancer (any) } \\
\hline No & 11,968 & $83.6 \%$ & 2341 & $16.4 \%$ & 14,309 \\
\hline Yes & 4876 & $80.7 \%$ & 1164 & $19.3 \%$ & 6040 \\
\hline \multicolumn{6}{|l|}{ Dementia } \\
\hline No & 13,355 & $81.2 \%$ & 3092 & $18.8 \%$ & 16,447 \\
\hline Yes & 3489 & $89.4 \%$ & 413 & $10.6 \%$ & 3902 \\
\hline \multicolumn{6}{|l|}{ Diabetes Mellitus } \\
\hline No & 10,571 & $83.1 \%$ & 2145 & $16.9 \%$ & 12,716 \\
\hline Yes & 6273 & $82.2 \%$ & 1360 & $17.8 \%$ & 7633 \\
\hline \multicolumn{6}{|l|}{ Mental Health (other) } \\
\hline No & 15,816 & $82.9 \%$ & 3268 & $17.1 \%$ & 19,084 \\
\hline Yes & 1028 & $81.3 \%$ & 237 & $18.7 \%$ & 1265 \\
\hline
\end{tabular}


Table 2 Cohort characteristics by pain severity in the last 30 days of life (Continued)

\begin{tabular}{|c|c|c|c|c|c|}
\hline & No severe daily pain & $(\%)$ & Severe daily pain & $(\%)$ & All \\
\hline & \multicolumn{2}{|l|}{ N } & \multicolumn{2}{|l|}{$\mathrm{N}$} & $\mathrm{N}$ \\
\hline \multicolumn{6}{|c|}{ Mood and Anxiety Disorders } \\
\hline No & 14,460 & $83.2 \%$ & 2926 & $16.8 \%$ & 17,386 \\
\hline Yes & 2384 & $80.5 \%$ & 579 & $19.5 \%$ & 2963 \\
\hline \multicolumn{6}{|c|}{ Osteo-arthritis } \\
\hline No & 7842 & $85.0 \%$ & 1384 & $15.0 \%$ & 9226 \\
\hline Yes & 9002 & $80.9 \%$ & 2121 & $19.1 \%$ & 11,123 \\
\hline \multicolumn{6}{|c|}{ Renal Failure } \\
\hline No & 13,855 & $83.3 \%$ & 2787 & $16.7 \%$ & 16,642 \\
\hline Yes & 2989 & $80.6 \%$ & 718 & $19.4 \%$ & 3707 \\
\hline \multicolumn{6}{|c|}{ Rheumatoid Arthritis } \\
\hline No & 16,066 & $83.1 \%$ & 3261 & $16.9 \%$ & 19,327 \\
\hline Yes & 778 & $76.1 \%$ & 244 & $23.9 \%$ & 1022 \\
\hline \multicolumn{6}{|l|}{ Stroke } \\
\hline No & 14,962 & $82.6 \%$ & 3146 & $17.4 \%$ & 18,108 \\
\hline Yes & 1882 & $84.0 \%$ & 359 & $16.0 \%$ & 2241 \\
\hline
\end{tabular}

apalliative Care

CHF) and sudden death had a lower proportion reporting severe daily pain than those with terminal illness (e.g., cancer) (Table 3). The following chronic conditions were associated with increased risk of severe daily pain (Table 2): rheumatoid arthritis (23.9\%), mood and anxiety disorders (19.5\%), renal failure (19.4\%), cancer (19.3\%), osteoarthritis (19.1\%) and other mental health illness (18.7). Many cardiac conditions (acute myocardial infarction, congestive heart failure, hypertension) as well as chronic neurological conditions [history of stroke (16.0\%) and dementia $(10.6 \%)]$ were associated with lower than average reports of severe daily pain.

Physical symptoms as reported on the RAI-HC associated with higher severe daily pain include dyspnea (19.2\%), anorexia (22.2\%), emesis (29.5\%), constipation $(31.4 \%)$ and edema (20.2\%) (Table 4). Increasing severity of pressure ulcers were also associated with higher rates of pain. Additionally, psychological symptoms such as loneliness and sad mood were associated with increased reports of severe daily pain.

\section{System factors}

A minority of decedents received designated palliative home care or a physician home visit between 30 days to 6 months prior to death, at 22.9 and $13.2 \%$ respectively. Decedents who received designated palliative home care had higher severe daily pain in the last 30 days of life than those without $(21.8 \%$ vs $15.9 \%)$. A trend was also demonstrated toward increased pain in those who received a physician home visit. Pain trended upward with time since self-reported admission to hospital with $14.8 \%$ of those in hospital versus $19.9 \%$ in those who had not reported a hospitalization in the previous 180 days.

Logistic regression models for odds of severe daily pain Adjusting for multiple covariates as listed in our methods, females had greater odds of having severe daily pain $[\mathrm{OR}=1.25 ; 95 \%$ Confidence Interval (CI): 1.16 to 1.35 ] (Table 5). The odds ratio of severe daily pain was 0.31 in the decedents aged $90+$ compared to 0-49 (95\% CI: 0.23 to 0.42). Those with severe or very severe cognitive impairment had an OR of 0.68 and 0.52 , respectively, compared to those who were cognitively intact. When examining disease trajectory, compared to frailty, those with terminal illness were more likely to report severe daily pain (OR 1.66, (95\% CI: 1.46 to 1.88 ). Decedents with designated palliative home care had greater odds of increased pain compared to those without [OR 1.13 (95\% CI: 1.03 to 1.24)]. Conversely, the trend seen with physician home visits was no longer statistically significant for specialist or non-specialist home visits when all covariates were accounted for [OR 1.12 (95\% CI: 0.99 to 1.26 ) and 1.14 (95\% CI: 0.91 to 1.44)].

\section{Discussion}

We examined the proportion of severe daily pain reported in the last 30 days of life using populationbased administrative databases. We observed that less than 1 in 5 decedents (17.2\%) report severe daily 
Table 3 Cohort characteristics by pain severity in the last 30 days of life

\begin{tabular}{|c|c|c|c|c|c|}
\hline & No severe daily pain & $(\%)$ & Severe daily pain & (\%) & All \\
\hline & \multicolumn{2}{|l|}{ N } & \multicolumn{2}{|l|}{ N } & $\mathrm{N}$ \\
\hline \multicolumn{6}{|l|}{$\mathrm{ADLS}^{\mathrm{a}}$} \\
\hline Independent & 3180 & $83.2 \%$ & 641 & $16.8 \%$ & 3821 \\
\hline Supervision required & 1475 & $82.4 \%$ & 316 & $17.6 \%$ & 1791 \\
\hline Limited impairment & 3113 & $83.1 \%$ & 633 & $16.9 \%$ & 3746 \\
\hline Extensive assistance required (I) & 1900 & $83.2 \%$ & 383 & $16.8 \%$ & 2283 \\
\hline Extensive assistance required (II) & 3017 & $83.4 \%$ & 602 & $16.6 \%$ & 3619 \\
\hline Dependent & 2760 & $80.5 \%$ & 667 & $19.5 \%$ & 3427 \\
\hline Total dependence & 1399 & $84.2 \%$ & 263 & $15.8 \%$ & 1662 \\
\hline \multicolumn{6}{|l|}{ IADLs ${ }^{b}$} \\
\hline No difficulty in any of three IADLs & 97 & $93.3 \%$ & 7 & $6.7 \%$ & 104 \\
\hline Some difficulty in one IADL but no difficulty in the other two & 158 & $88.3 \%$ & 21 & $11.7 \%$ & 179 \\
\hline Some difficulty in two IADLs but no difficulty in the other one & 474 & $85.3 \%$ & 82 & $14.7 \%$ & 556 \\
\hline Some difficulty in all three IADLs & 94 & $89.5 \%$ & 11 & $10.5 \%$ & 105 \\
\hline Great difficulty in one IADL but less than great difficulty in the other two & 1240 & $82.0 \%$ & 273 & $18.0 \%$ & 1513 \\
\hline Great difficulty in two IADLs but less than great difficulty in the other one & 7373 & $79.9 \%$ & 1856 & $20.1 \%$ & 9229 \\
\hline Great difficulty in all three IADLs & 7408 & $85.5 \%$ & 1255 & $14.5 \%$ & 8663 \\
\hline \multicolumn{6}{|l|}{ Cognitive Performance Scale (CPS) } \\
\hline Intact & 3230 & $79.7 \%$ & 824 & $20.3 \%$ & 4054 \\
\hline Borderline intact & 2260 & $79.2 \%$ & 595 & $20.8 \%$ & 2855 \\
\hline Mild impairment & 5853 & $82.1 \%$ & 1275 & $17.9 \%$ & 7128 \\
\hline Moderate impairment & 2395 & $86.3 \%$ & 381 & $13.7 \%$ & 2776 \\
\hline Moderate/severe impairment & 722 & $88.4 \%$ & 95 & $11.6 \%$ & 817 \\
\hline Severe impairment & 1352 & $88.1 \%$ & 183 & $11.9 \%$ & 1535 \\
\hline Very severe impairment & 1032 & $87.2 \%$ & 152 & $12.8 \%$ & 1184 \\
\hline \multicolumn{6}{|l|}{ Caregiver Stress } \\
\hline Yes & 7383 & $81.7 \%$ & 1652 & $18.3 \%$ & 9035 \\
\hline No & 9461 & $83.6 \%$ & 1853 & $16.4 \%$ & 11,314 \\
\hline \multicolumn{6}{|l|}{ Where Lived at Time of Referral } \\
\hline Missing & 8659 & $83.2 \%$ & 1747 & $16.8 \%$ & 10,406 \\
\hline Private home/apt. With no home care services & 5184 & $81.8 \%$ & 1156 & $18.2 \%$ & 6340 \\
\hline Private home/apt. With home care services & 1803 & $82.5 \%$ & 383 & $17.5 \%$ & 2186 \\
\hline Board and care/assisted living/group home & 768 & $84.1 \%$ & 145 & $15.9 \%$ & 913 \\
\hline Residential care facility & 241 & $85.5 \%$ & 41 & $14.5 \%$ & 282 \\
\hline Other & 189 & $85.1 \%$ & 33 & $14.9 \%$ & 222 \\
\hline \multicolumn{6}{|l|}{ Who Lived with at Time of Referral } \\
\hline Missing & 8659 & $83.2 \%$ & 1747 & $16.8 \%$ & 10,406 \\
\hline Lived alone & 2300 & $82.9 \%$ & 476 & $17.1 \%$ & 2776 \\
\hline Lived with spouse only & 2798 & $81.6 \%$ & 633 & $18.4 \%$ & 3431 \\
\hline Lived with spouse and other(s) & 666 & $81.0 \%$ & 156 & $19.0 \%$ & 822 \\
\hline Lived with child (not spouse) & 1105 & $81.3 \%$ & 254.0 & $18.7 \%$ & 1359 \\
\hline Lived with other(s) (not spouse or children) & 572 & $84.5 \%$ & 105 & $15.5 \%$ & 677 \\
\hline Lived in group setting with non-relative(s) & 744 & $84.7 \%$ & 134 & $15.3 \%$ & 878 \\
\hline
\end{tabular}


Table 3 Cohort characteristics by pain severity in the last 30 days of life (Continued)

\begin{tabular}{|c|c|c|c|c|c|}
\hline & No severe daily pain & (\%) & Severe daily pain & (\%) & All \\
\hline & \multicolumn{2}{|l|}{ N } & \multicolumn{2}{|l|}{$\mathrm{N}$} & $\mathrm{N}$ \\
\hline \multicolumn{6}{|c|}{ Disease Trajectoryc } \\
\hline Frailty & 3317 & $87.3 \%$ & 481 & $12.7 \%$ & 3798 \\
\hline Organ Failure & 7596 & $85.0 \%$ & 1344 & $15.0 \%$ & 8940 \\
\hline Sudden Death & 671 & $83.4 \%$ & 134 & $16.6 \%$ & 805 \\
\hline Undetermined & 323 & $83.0 \%$ & 66 & $17.0 \%$ & 389 \\
\hline Other & 531 & $79.5 \%$ & 137 & $20.5 \%$ & 668 \\
\hline Terminal IIIness & 4406 & $76.6 \%$ & 1343 & $23.4 \%$ & 5749 \\
\hline
\end{tabular}

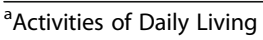

Extensive assistance-Client performed part of activity on own (50\% or more of subtasks), but help of following type(s) were provided 3 or more times: (I) Weight-bearing support-OR-

(II) Full performance by another during part (but not all) of last 3 days

Dependent-Client involved and completed less than $50 \%$ of subtasks on own (includes $2+$ person assist), received weight bearing help

Total dependence-Full performance of activity by another

Instrumental Activities of Daily Living

'Disease trajectories - frailty (e.g., dementia), organ failure (e.g., congestive heart failure), terminal illness (e.g., cancer)

pain. This level of pain is considered inadequately treated and would likely be associated with lower quality of life and functional impairment [37, 38]. We identified multiple demographic, clinical and system factors associated with increased end-of-life pain, many of which have not been previously described. Notably, disease trajectory impacted reported severe daily pain at the end of life. Those with terminal illness (i.e. cancer) and other had higher odds of reporting pain than those with frailty, sudden death or organ failure (cardiac or pulmonary). Interestingly, renal failure is categorized into the other disease trajectory and was associated with increased reported pain. Although this is a condition that is not typically considered inherently painful, it is possible that pain in this population may be undertreated, possibly due to fear of using analgesic medications that may worsen renal function or are renally cleared. Additionally, increased pain reported by females and younger decedents could be hypothesized to be related to the specific illness or trajectory related to these populations; however, this trend is persistent when disease trajectory was accounted for. The increased reported pain in those receiving palliative services may have been related to referral bias where those with increased pain are more likely to receive a palliative care referral. However, only a small minority received a palliative home care designation or physician home visit despite being close to death. This is consistent with other jurisdictions signaling large room for improvement in access to palliative care services $[35,40]$.

Our study addresses a gap in the previous literature by examining end-of-life pain in a large sample, using a validated pain scale and conducting analyses adjusting for multiple potential confounders. The proportion of pain reported in this study is lower than previously reported by other population research [21]. This may be attributed to our study examining those with daily severe pain compared to previous research including intensity (moderate-severe) but not considering frequency when determining clinical significance. Previous studies [11-13, 21] have demonstrated an association between pain and select comorbidities: arthritis, cancers and mental health conditions, which was again shown in our population. We demonstrated lower reported pain in persons with neurological impairment (dementia and post-stroke). Decreased reported pain in those with reduced cognitive functioning was maintained with confounders such as age, frailty and gender accounted for. This is consistent with previous studies demonstrating that pain may be underreported in those with cognitive impairment $[18,19]$. It is difficult to infer if perceived pain levels are in fact lower or if those with cognitive impairment are unable to vocalize pain.

\section{Strengths and limitations}

We examined a wide array of health care services at the end of life for a large, population-based decedent cohort. This is possible in Ontario, comprising of approximately $40 \%$ of the Canadian population, where well-developed health administrative databases are linked at an individual level for a range of publiclyfunded health services. Previous studies have focused on specific populations or had limited access to other health care services utilized by decedents. We recognize the data used for this study is relatively old, although there were no significant policy or practice changes since 2015 that would reasonably be expected to influence the relevance of our findings to current 
Table 4 Symptomology self-reported in RAl- $\mathrm{HC}^{\mathrm{a}}$ by pain severity in the last 30 days of life

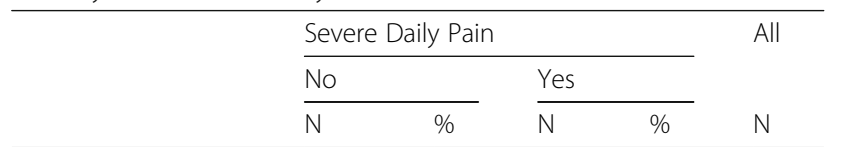

Shortness of Breath

No

Yes

Loss of Appetite

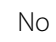

Yes

Vomiting

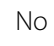

Yes

\section{Constipation}

No

Yes

Delusions

No

Yes

Hallucinations

No

Yes

Sad Mood

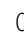

Pressure Ulcer ${ }^{c}$

$\begin{array}{llllll}0 & 13,824 & 83.6 & 2718 & 16.4 & 16,542 \\ 1 & 1595 & 81.7 & 357 & 18.3 & 1952 \\ 2 & 1066 & 79.1 & 282 & 20.9 & 1348 \\ 3 & 254 & 73.8 & 90 & 26.2 & 344 \\ 4 & 105 & 64.4 & 58 & 35.6 & 163 \\ \text { Edema } & & & & & \\ \text { No } & 10,689 & 84.6 & 1943 & 15.4 & 12,632 \\ \text { Yes } & 6155 & 79.8 & 1562 & 20.2 & 7717 \\ \text { loneliness } & & & & & \\ \text { Unknown } & 4879 & 85.2 & 845 & 14.8 & 5724 \\ \text { No } & 10,826 & 82.5 & 2303 & 17.5 & 13,129 \\ \text { Yes } & 1139 & 76.1 & 357 & 23.9 & 1496\end{array}$

\section{Client Felt/Was Advised to Reduce Drinking}

No

Yes

$271 \quad 82.1$

Compliance/Adherence With Medications

Always Compliant

14,905

83.0

Compliant $>80 \%$
1427
3059

3446

59

36
Table 4 Symptomology self-reported in $\mathrm{RAI}^{-\mathrm{HC}^{\mathrm{a}}}$ by pain severity in the last 30 days of life (Continued)

\begin{tabular}{|c|c|c|c|c|c|}
\hline & \multicolumn{4}{|c|}{ Severe Daily Pain } & \multirow{3}{*}{$\begin{array}{l}\text { All } \\
\mathrm{N}\end{array}$} \\
\hline & \multicolumn{2}{|l|}{$\mathrm{No}$} & \multicolumn{2}{|l|}{ Yes } & \\
\hline & $N$ & $\%$ & $\mathrm{~N}$ & $\%$ & \\
\hline Compliant < 80\% & 355 & 82.9 & 73 & 17.1 & 428 \\
\hline No Medications & 157 & 94.6 & 9 & 5.4 & 166 \\
\hline \multicolumn{6}{|c|}{ Time Since Last Hospital Stay } \\
\hline Missing & 8659 & 83.2 & 1747 & 16.8 & 10,406 \\
\hline In hospital & 2923 & 85.2 & 509 & 14.8 & 3432 \\
\hline$>180$ days & 1626 & 80.1 & 404 & 19.9 & 2030 \\
\hline Within last week & 1045 & 81.8 & 232 & 18.2 & 1277 \\
\hline Within 8-14 days & 920 & 84.7 & 166 & 15.3 & 1086 \\
\hline Within 15-30 days & 827 & 82.1 & 180 & 17.9 & 1007 \\
\hline More than 30 days & 844 & 76.0 & 267 & 24.0 & 1111 \\
\hline
\end{tabular}

${ }^{a}$ Resident Assessment Instrument-Home Care

${ }^{\mathrm{b}}$ Sad Mood- 0 . Indicator not exhibited in last 3 days, 1. Exhibited 1-2 of last 3 days 2. Exhibited on each of last 3 days

'Presence of an ulcer anywhere on the body. Ulcers include any area of persistent skin redness (Stage 1); partial loss of skin layers (Stage 2); deep craters in the skin (Stage 3); breaks in skin exposing muscle or bone (Stage 4). [Code 0 if no ulcer, otherwise record the highest ulcer stage (Stage 1-4)

practice. While used widely as a clinical assessment tool in many settings, we also acknowledge that the validation for the RAI-HC pain scale was completed in elderly patients in nursing homes, potentially limiting the generalizability of this scale. Additionally, one of our primary limitations is that our data is collected from those who have received a RAI-HC assessment in the last month of life. This may limit the generalizability to those in long-term care home (nursing home), community, or hospital settings who have not been assessed for publicly funded home services (about $40 \%$ of decedent population) [41]. This approach also does not capture palliative home care received through private (out-of-pocket) expenses or nurse practitioner palliative home visits. Nevertheless, the RAI-HC provided us with a rare large population-based cohort that contained detailed information about patient-centered variables and outcomes (symptoms, living arrangements, caregiver information), beyond what has previously been presented in literature.

\section{Conclusion}

We observed multiple demographic, clinical and system factors associated with increased pain at the end of life. Clinicians should recognize severe daily pain is common but perhaps not proportional to the fear of suffering in pain that many experience when contemplating end of life [2]. Regardless this is still a 
Table 5 Multivariate logistic regression for factors associated with severe daily pain among the last 30 days of life

\begin{tabular}{|c|c|c|c|}
\hline Effect & $\begin{array}{l}\text { Odds } \\
\text { Ratio } \\
\text { Estimate }\end{array}$ & $\begin{array}{l}\text { Lower } 95 \% \\
\text { Confidence Limit for Odds Ratio }\end{array}$ & $\begin{array}{l}\text { Upper } 95 \% \\
\text { Confidence Limit for Odds Ratio }\end{array}$ \\
\hline \multicolumn{4}{|l|}{ Age } \\
\hline $0-49$ & ref & ref & ref \\
\hline $50-59$ & 0.79 & 0.58 & 1.08 \\
\hline $60-69$ & 0.60 & 0.45 & 0.80 \\
\hline 70-79 & 0.44 & 0.33 & 0.59 \\
\hline $80-89$ & 0.36 & 0.27 & 0.47 \\
\hline $90+$ & 0.31 & 0.23 & 0.42 \\
\hline \multicolumn{4}{|l|}{ Sex } \\
\hline Male & ref & ref & ref \\
\hline Female & 1.25 & 1.16 & 1.35 \\
\hline \multicolumn{4}{|l|}{ Income Quintile } \\
\hline Highest & ref & ref & ref \\
\hline High & 1.10 & 0.97 & 1.24 \\
\hline Middle & 1.07 & 0.94 & 1.21 \\
\hline Low & 1.03 & 0.92 & 1.17 \\
\hline Lowest & 1.08 & 0.95 & 1.21 \\
\hline \multicolumn{4}{|l|}{ Rurality } \\
\hline Urban & ref & ref & ref \\
\hline Rural & 0.98 & 0.89 & 1.08 \\
\hline \multicolumn{4}{|l|}{$A D L s^{a}$} \\
\hline Independent & ref & ref & ref \\
\hline Limited impairment & 1.12 & 0.98 & 1.28 \\
\hline Supervision required & 1.10 & 0.94 & 1.29 \\
\hline Extensive assistance required (I) & 1.26 & 1.08 & 1.46 \\
\hline Extensive assistance required (II) & 1.31 & 1.13 & 1.51 \\
\hline Dependent & 1.76 & 1.53 & 2.04 \\
\hline Total dependence & 2.05 & 1.63 & 2.59 \\
\hline \multicolumn{4}{|l|}{ IADLs ${ }^{b}$} \\
\hline No difficulty in any of three IADLs & ref & ref & ref \\
\hline Some difficulty in one IADL only & 2.04 & 0.83 & 5.03 \\
\hline Some difficulty in two IADLs only & 2.69 & 1.20 & 6.04 \\
\hline Some difficulty in all three IADLs & 2.16 & 0.80 & 5.87 \\
\hline $\begin{array}{l}\text { Great difficulty in one IADL but less than } \\
\text { great difficulty in the other two }\end{array}$ & 3.57 & 1.63 & 7.83 \\
\hline $\begin{array}{l}\text { Great difficulty in two IADLs but less } \\
\text { than great difficulty in the other one }\end{array}$ & 3.90 & 1.79 & 8.51 \\
\hline Great difficulty in all three IADLs & 3.09 & 1.41 & 6.77 \\
\hline \multicolumn{4}{|l|}{ Palliative Home Care } \\
\hline No & ref & ref & ref \\
\hline Yes & 1.13 & 1.03 & 1.24 \\
\hline \multicolumn{4}{|l|}{ Physician Home Visit } \\
\hline No Physician Home Visit & ref & ref & ref \\
\hline Physician Home Visit Non Specialist & 1.12 & 0.99 & 1.26 \\
\hline
\end{tabular}


Table 5 Multivariate logistic regression for factors associated with severe daily pain among the last 30 days of life (Continued)

\begin{tabular}{|c|c|c|c|}
\hline Effect & $\begin{array}{l}\text { Odds } \\
\text { Ratio } \\
\text { Estimate }\end{array}$ & $\begin{array}{l}\text { Lower } 95 \% \\
\text { Confidence Limit for Odds Ratio }\end{array}$ & $\begin{array}{l}\text { Upper } 95 \% \\
\text { Confidence Limit for Odds Ratio }\end{array}$ \\
\hline Palliative Care Specialist & 1.14 & 0.91 & 1.44 \\
\hline \multicolumn{4}{|c|}{ Cognitive Performance Scale (CPS) } \\
\hline Intact & ref & ref & ref \\
\hline Borderline intact & 1.10 & 0.97 & 1.24 \\
\hline Mild impairment & 0.97 & 0.88 & 1.08 \\
\hline Moderate impairment & 0.75 & 0.65 & 0.87 \\
\hline Moderate/severe impairment & 0.61 & 0.48 & 0.78 \\
\hline Severe impairment & 0.68 & 0.56 & 0.82 \\
\hline Very severe impairment & 0.52 & 0.40 & 0.68 \\
\hline \multicolumn{4}{|l|}{ Number of Chronic Conditions } \\
\hline $0-2$ & ref & ref & ref \\
\hline $3-4$ & 1.09 & 0.98 & 1.21 \\
\hline $5+$ & 1.34 & 1.21 & 1.49 \\
\hline \multicolumn{4}{|l|}{ Trajectory } \\
\hline Frailty & ref & ref & ref \\
\hline Organ Failure & 1.06 & 0.94 & 1.19 \\
\hline Sudden Death & 1.28 & 1.04 & 1.58 \\
\hline Undetermined & 1.26 & 0.95 & 1.68 \\
\hline Other & 1.59 & 1.28 & 1.97 \\
\hline Terminal IIIness & 1.66 & 1.46 & 1.88 \\
\hline
\end{tabular}

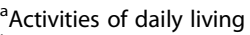

bInstrumental activities of daily living

significant number of people who report severe pain, and prompt screening and management of pain should be considered, particularly for those with increased risk factors. Improvements in access and quality of care likely would reduce the prevalence of severe pain at the end of life, given previous studies showing large gaps in palliative care provision [41].

\section{Supplementary information}

Supplementary information accompanies this paper at https://doi.org/10. 1186/s12904-020-00569-2.

Additional file 1. Databases held at ICES used in this study. Includes database name and a description of the type of data (variables) obtained from each database.

Additional file 2. Definitions of Palliative Home Care and Palliative Physician Home Visits. Includes a list and description of billing (physician) and service (home care) codes used to determine if a patient received either service.

\section{Abbreviations}

CHF: Congestive heart failure; COPD: Chronic obstructive pulmonary disease; RAI-HC: Resident assessment instrument - home care; ADLs: Activities of daily living; IADLs: Instrumental activities of daily living; RPDB: Registered Persons Database; ORGD: Ontario Registrar General Database; ICD-

10: International classification of diseases; OHIP: Ontario health insurance plan; CPS: Cognitive performance scale; OR: Odds ratio; Cl: Confidence interval

\section{Acknowledgments}

Not applicable.

Authors' contributions

All authors had access to all of the data in the study and take responsibility for the integrity of the data and the accuracy of the data analysis. $\mathrm{MH}, \mathrm{SB}$, and PT conceived and designed the study. RT acquired the data and conducted statistical analysis. MH, SB, RT, JL, and PT interpreted the data. MH drafted the manuscript. All authors provided revisions for important intellectual content and approved the final version for publication.

\section{Funding}

This research was supported by a research grant from the Bruyère Centre for Individualized Health and from the Ontario Ministry of Health and LongTerm Care (MOHLTC) to the Ontario QUILT (QUality for Individuals who require Long-Term support) Network (grant ID \#255). This study was also supported by ICES, which is funded by an annual grant from the Ontario MOHLTC. The views expressed in this paper are the views of the authors and do not necessarily reflect those of the funders. The funders had no influence on the design and conduct of the study; collection, management, analysis, and interpretation of the data; and preparation, review, or approval of the manuscript.

\section{Availability of data and materials}

The data that support the findings of this study are available from ICES, but restrictions apply to the availability of these data according to ICES policies and provincial and federal privacy laws to protect individual patient data, and so are not publicly available. As the data custodian, all requests for data 
should go through ICES. Please contact the corresponding author (PT) should you have questions about accessing study data.

\section{Ethics approval and consent to participate}

Ethics approval was obtained from the Sunnybrook Health Sciences Centre Research Ethics Board in Toronto, Canada and from the Ottawa Health Science Network Research Ethics Board in Ottawa, Canada.

\section{Consent for publication}

Not applicable.

\section{Competing interests}

The authors declare they have no competing interests.

\section{Author details}

'Department of Medicine, Division of Palliative Care, University of Ottawa, Ottawa, Ontario, Canada. ${ }^{2}$ Bruyère Research Institute, Ottawa, Ontario, Canada. ${ }^{3}$ Ottawa Hospital Research Institute, 1053 Carling Avenue, Ottawa, ON K1Y4E9, Canada. ${ }^{4}$ ICES, Population Health and Primary Care, Ottawa, Ontario, Canada.

Received: 19 November 2019 Accepted: 24 April 2020 Published online: 30 April 2020

\section{References}

1. Steinhauser KE, Christakis NA, Clipp EC, McNeilly M, Mclntyre L, Tulsky JA Factors considered important at the end of life by patients, family, physicians, and other care providers. JAMA. 2000;284(19):2476-82.

2. BMA End-of-Life Care and Physician-Assisted Dying Steering Group: End-oflife care and physician-assisted dying. 3 Reflections and recommendations, https://www.bma.org.uk/endoflifecare. Accessed 17 November 2018.

3. Boström B, Sandh M, Lundberg D, Fridlund B. Cancer-related pain in palliative care: patients' perceptions of pain management. J Adv Nurs. 2004; 45(4):410-9.

4. Kaasa $\mathrm{S}$, Loge JH. Quality of life in palliative care: principles and practice Palliat Med. 2003;17(1):11-20.

5. Von Gunten CF. Interventions to manage symptoms at the end of life. J Palliat Med. 2005;8(Suppl 1):s88-94

6. Yang GM, Ewing G, Booth S. What is the role of specialist palliative care in an acute hospital setting? A qualitative study exploring views of patients and carers. Palliat Med. 2012;26(8):1011-7.

7. Barbera L, Taylor C, Dudgeon D. Why do patients with cancer visit the emergency department near the end of life? Can Med Assoc J. 2010;182(6): 563-8.

8. Gonzales MJ, Pantilat SZ. Pain at the end of life. Hosp Med Clin. 2012;1(1): e109-23.

9. Johnson CE, Girgis A, Paul CL, Currow DC. Cancer specialists' palliative care referral practices and perceptions: results of a national survey. Palliat Med. 2008;22(1):51-7.

10. Higginson IJ, Finlay IG, Goodwin DM, Hood K, Edwards AG, Cook A, et al. Is there evidence that palliative care teams alter end-of-life experiences of patients and their caregivers? J Pain Symptom Manag. 2003;25(2):150-68

11. Van den Beuken-van Everdingen MHJ, De Rijke JM, Kessels AG, Schouten HC, van Kleef M, Patin J. Prevalence of pain in patients with cancer: a systematic review of the past 40 years. Ann Oncol. 2007;18(9):1437-49.

12. Spiegel D, Sands S, Koopman C. Pain and depression in patients with cancer. Cancer. 1994:74(9):2570-8.

13. Delgado-Guay M, Parsons HA, Li Z, Palmer JL, Bruera E. Symptom distress in advanced cancer patients with anxiety and depression in the palliative care setting. Support Care Cancer. 2009;17(5):573-9.

14. Laird BJA, Scott AC, Colvin LA, McKeon AL, Murray GD, Fearon KC, et al. Pain, depression, and fatigue as a symptom cluster in advanced cancer. J Pain Symptom Manag. 2011;42(1):1-11.

15. Solano JP, Gomes B, Higginson IJ. A comparison of symptom prevalence in far advanced cancer, AIDS, heart disease, chronic obstructive pulmonary disease and renal disease. J Pain Symptom Manag. 2006:31(1):58-69.

16. Murtagh FEM, Addington-Hall J, Higginson IJ. The prevalence of symptoms in end-stage renal disease: a systematic review. Adv Chronic Kidney Dis. 2007;14(1):82-99.
17. Zambroski CH, Moser DK, Bhat G, Ziegler C. Impact of symptom prevalence and symptom burden on quality of life in patients with heart failure. Eur J Cardiovasc Nurs. 2005;4(3):198-206.

18. Radbruch L, Sabatowski R, Loick G, Jonen-Thielemann I, Kasper M, Gondek $B$, et al. Cognitive impairment and its influence on pain and symptom assessment in a palliative care unit: development of a minimal documentation system. Palliat Med. 2000;14(4):266-76.

19. Dubé CE, Mack DS, Hunnicutt JN, Lapane KL. Cognitive impairment and pain among nursing home residents with cancer. J Pain Symptom Manag. 2018;55(6):1509-18.

20. Seow H, O'Leary E, Perez R, Tanuseputro P. Access to palliative care by disease trajectory: a population-based cohort of Ontario decedents. BM Open. 2018;8(4):e021147.

21. Smith AK, Cenzer IS, Knight SJ, Puntillo KA, Widera E, Williams BA, et al. The epidemiology of pain during the last 2 years of life. Ann Intern Med. 2010; 153(9):563-9.

22. Home Care $(\mathrm{HC})$ - interRAl, http://www.interrai.org/home-care.html. Accessed 17 November 2018.

23. Describing Outcome Scales (RAI-MDS 2.0). Canadian Institute for Health Information, https://www.cihi.ca/en/outcome_rai-mds_2.0_en.pdf. Accessed 17 November 2018.

24. Muggah E, Graves E, Bennett C, Manuel DG. The impact of multiple chronic diseases on ambulatory care use; a population based study in Ontario, Canada. BMC Health Serv Res. 2012;12:452.

25. Thavorn K, Maxwell CJ, Gruneir A, Bronskill SE, Bai Y, Pefoyo AJK, et al. Effect of socio-demographic factors on the association between multimorbidity and healthcare costs: a population-based, retrospective cohort study. BMJ Open. 2017;7(10):e017264

26. Mondor L, Maxwell CJ, Hogan DB, Bronskill SE, Gruneir A, Lane NE, et al. Multimorbidity and healthcare utilization among home care clients with dementia in Ontario, Canada: a retrospective analysis of a population-based cohort. PLoS Med. 2017;14(3):e1002249.

27. Petrosyan Y, Bai YQ, Pefoyo AJK, Gruneir A, Thavorn K, Maxwell CJ, et al. The relationship between diabetes care quality and diabetes-related hospitalizations and the modifying role of comorbidity. Can J Diabetes. 2017:41(1):17-25.

28. Mondor L, Maxwell CJ, Bronskill SE, Gruneir A, Wodchis WP. The relative impact of chronic conditions and multimorbidity on health-related quality of life in Ontario long-stay home care clients. Qual Life Res. 2016;25(10): 2619-32.

29. Lane NE, Maxwell CJ, Gruneir A, Bronskill SE, Wodchis WP. Absence of a socioeconomic gradient in older adults' survival with multiple chronic conditions. EBioMedicine. 2015:2(12):2094-100.

30. Gruneir A, Bronskill SE, Maxwell CJ, Bai YQ, Kone AJ, Thavorn K, et al. The association between multimorbidity and hospitalization is modified by individual demographics and physician continuity of care: a retrospective cohort study. BMC Health Serv Res. 2016:16:154

31. Pefoyo AJK, Bronskill SE, Gruneir A, Calzavara A, Thavorn K, Petrosyan Y, et al. The increasing burden and complexity of multimorbidity. BMC Public Health. 2015;15:415.

32. Lunney JR, Lynn J, Foley DJ, Lipson S, Guralnik JM. Patterns of functional decline at the end of life. JAMA. 2003;289(18):2387-92.

33. Vital Statistics - Death Database (CVSD). Statistics Canada, http//www23. statcan.gc.ca/imdb/p2SV.pl? Function=getSurvey\&SDDS=5047 (2011, accessed 19 March 2020).

34. Fassbender K, Fainsinger RL, Carson M, Finegan BA. Cost trajectories at the end of life: the Canadian experience. J Pain Symptom Manag. 2009;38(1):7580 .

35. Tanuseputro P, Beach S, Chalifoux M, Wodchis WP, Hsu AT, Seow $H$, et al. Associations between physician home visits for the dying and place of death: a population-based retrospective cohort study. PLoS One. 2018;13(2): e0191322.

36. Fries BE, Simon SE, Morris JN, Flodstrom C, Bookstein FL. Pain in U.S. nursing homes: validating a pain scale for the minimum data set. Gerontologist. 2001;41(2):173-9.

37. Wang XS, Cleeland CS, Mendoza TR, Engstrom MC, Liu S, Xu G, et al. The effects of pain severity on health-related quality of life: a study of Chinese cancer patients. Cancer Interdiscip Int J Am Cancer Soc. 1999:86(9):1848-55.

38. Serlin RC, Mendoza TR, Nakamura Y, Edwards KR, Cleeland CS. When is cancer pain mild, moderate or severe? Grading pain severity by its interference with function. Pain. 1995;61(2):277-84. 
39. Morris JN, Fries BE, Mehr DR, Hawes C, Phillips C, Mor V, et al. MDS cognitive performance scale@. J Gerontol. 1994;49(4):M174-82.

40. Åbom B, Kragstrup J, Vondeling H, Bakketeig LS, Stovring H. Defining cancer patients as being in the terminal phase: who receives a formal diagnosis, and what are the effects? I Clin Oncol. 2005;23(30):7411-6.

41. Tanuseputro P, Budhwani S, Bai YQ, Wodchis WP. Palliative care delivery across health sectors: a population-level observational study. Palliat Med. 2017;31(3):247-57

\section{Publisher's Note}

Springer Nature remains neutral with regard to jurisdictional claims in published maps and institutional affiliations.

- fast, convenient online submission

- thorough peer review by experienced researchers in your field

- rapid publication on acceptance

- support for research data, including large and complex data types

- gold Open Access which fosters wider collaboration and increased citations

- maximum visibility for your research: over $100 \mathrm{M}$ website views per year

At $\mathrm{BMC}$, research is always in progress. 